\title{
Experiences of International PhD Students in Den- mark as Quest Stories
}

\author{
Tijana Maksimovic, PhD Fellow, PhD Student, Danish School of Education, Aarhus University \\ Sofie Kobayashi, Assistant Professor, Department of Science Education, University of Copenhagen
}

\section{Research article, peer reviewed}

This article explores how the metaphor of quest can be used to conceptualise PhD experience and be employed in PhD supervision practice. As part of a small-scale study of the PhD experience of international students in Denmark, whose numbers have significantly increased in recent years, we conducted narrative interviews with nine doctoral students. They were asked to select and describe up to five photographs that represent what they will remember about their PhDs. These narratives were first analysed inductively and then deductively organised using the quest metaphor. The findings indicate that the quest metaphor can capture the complexity of the PhD experience and provide a starting point for discussion. However, it also presents certain limitations, so one direction for future studies might be to combine 'quest' with other metaphors.

\section{Background}

This study explores the metaphor of 'quest' as a means for grasping the complexity of the experiences of international PhD students in Denmark. Following the 2006 decision to increase the intake of doctoral students in this country, their number has doubled, with the largest growth (60\%) among Science, Technology and Mathematics (STEM) students (Universities Denmark, 2013). At the same time, almost one in three STEM PhD students are international (Danish Council for Research Policy, 2011), following efforts to attract and retain more international students. This influx of international PhD students makes the PhD experience a relevant area of research, but at present it remains under studied.

In Denmark, and especially within STEM, PhD scholarships are funded through research projects, and PhD students are recruited through international advertisements for PhD studentships. Hence, they are simultaneously students enrolled in a PhD school and employees at the university. As noted, there is little literature on the experiences of these students once in Denmark. The studies that do exist include Bøgelund (2015) who explored how supervisors perceive and handle the changing conditions and specific challenges they encounter in cross-cultural supervision. Mosneaga \& Winther (2013), meanwhile, researched the views of international master and PhD students in relation to their career prospects.

Internationally, there are a growing number of studies that look at PhD experience. These include studies that focus on supervision, exploring the inherent complexities and problematic nature of supervising students from a culture different from the (commonly) privileged tradition of Western academia; see, for instance, Barron and Zeegers (2006); Cargill (2000); and Manathunga (2014) who investigate supervision as interaction. Challenges and strategies for overcoming difficulties are the focus of most of studies researching the PhD students' experiences, such as Cotterall (2013), Ingleton and Cadman (2002) or Winchester-Seeto et al. (2014). Results from this research suggest that the process of writing and supervision are recognised as the 
main sites of tension and emotional challenges for international PhD students (Cotterall, 2013), while their confidence and sense of agency are affected by various emotional and social factors, including family responsibilities and maintaining networks in the home country (Cadman, 2002). Winchester-Seeto et al. (2014) identified eight factors that make PhD studies more difficult for international students: language; cultural differences in dealing with hierarchy; separation from the familiar; separation from support; other cultural differences; stereotypes; time; and what happens when the candidate returns home. They framed the difficulties that international students experience as 'intensifiers'; domestic students are found to experience many of the same difficulties, but not with the same intensity.

PhD students adopt a range of strategies for completing their studies. Kiley (2003) found that some PhD students take a strategic approach and adapt their research and writing to the discourse of the host country, but preserve their world view and revert to it as they return to their home country. Another identified approach is to maintain original ways of thinking, while others yet internalise the world views and ways of thinking of the host country and hence transform their own thinking. Elliot, Baumfield and Reid (2016) describe the creation of a 'third space' as a strategy for PhD students to find room for recreation outside their studies. Findings also highlight the importance of peers and informal activities for the development of academic identity, which tend to fall outside the formal and structured remit of most PhD programmes (McAlpine, Amundsen, \& Turner, 2013). Mantai and Dowling (2015) distinguish between three types of support as important for PhD students' success; emotional, academic and instrumental provided from supervisors, peers and family alike. Furthermore, research groups are identified as supportive structures that provide a microclimate for inclusion (Walsh, 2010). Few studies have explored the joys and excitements of PhD work; Elliot, Reid \& Baumfield (2016) are an exception, exploring successful early career researchers' experiences of their PhD time. The picture we get from international research into the experiences of international PhD students is very complex and multifaceted. Although there is little research concerning international PhD students' experiences in Denmark, we assume that they would not differ from the experiences from other countries in this regard.

Metaphors can be powerful in grasping complex situations as they help create meaning at many levels. Metaphors abound in descriptions of $\mathrm{PhD}$ education and supervision, reflecting the complexity and ambivalence of this area (Lee \& Green, 2009). The PhD experience is described as a landscape 'populated with bridges, chasms, mountains and archways, and traversed by a plenitude of journeys, punctuated by juggling and balancing, marked by rites and rituals, and filled with darkness and light' (p. 617). In this study we focus on how metaphors can be used to gain insight into the complex experiences of international PhD students in Denmark.

Although the metaphor of a journey is commonly used to describe doctoral education, McCulloch (2013) argues that it is too simplistic and cannot capture the complexity. Instead, he proposes the metaphor of 'quest' to discuss and understand the messy experience of PhD studies. This metaphor is borrowed from the poet W. H. Auden's essay on literary heroes, in which he distinguishes six elements that form part of a heroic quest: a precious object to be found, a long journey to find it, a hero, a series of tests, the guardians of the object, and the helpers to assist the hero. McCulloch (2013) argues that quest can be identified in many cultural traditions, and hence is very suitable as a metaphor for analysing and describing experiences of international students. Using it can provide us with a complex, yet structured image of international PhD stu- 
dents' experiences, which leads us to the aim of this study - to explore how the quest metaphor can be used as a means to grasp the complexity of the experiences of international PhD students in Denmark.

\section{Methods}

This study is part of an on-going longitudinal study, which looks into the career decision-making process of international PhD students in Denmark, i.e. non-Danish individuals who moved to Denmark to study. With a focus on the period of transition from doctoral education to a post$\mathrm{PhD}$ career, within or outside academia, the longitudinal study aims to explore what meaning the $\mathrm{PhD}$ experience has for the participants, especially in relation to their further career. Starting from a thematic analysis of the students' accounts of the most memorable aspects of their doctoral studies, we proceed to employ the 'quest' metaphor to organise the resulting themes and see if it can be used to conceptualise stories of $\mathrm{PhD}$ experience in a meaningful way.

\section{Participants}

The criteria used to select participants for the broader study were that they were international (arrived in Denmark to study), that they were close to finishing their studies, and that they were willing to participate in interviews over the planned period (12-15 months). The total number of participants (nine for the whole of the study) was limited because of the in-depth qualitative nature of the project and its narrative approach.

The broader longitudinal study explores how PhD students coming to Denmark from abroad navigate and take decisions in a new context, so their cultural background was not in focus. The students who agreed to partake in the study came from Europe (seven) and South America (two), and the majority of them - six - arrived in Denmark for their PhD studies. They were all full-time employees at the university during their doctoral studies, as is common practice for PhD students in Denmark. The educational background of most of the participants was in natural sciences (biology, chemistry, physics); one was an engineer and one was a veterinarian.

The aim of the study is not to use the findings to generalize and make claims that could be universally applicable to experiences of international PhD students. Instead, the small number of participants offers the opportunity to contextualize the findings and provide richer insights into the complexity of individual circumstances. Participants were recruited through an open invitation. They identified themselves as international PhD students, and as they volunteered to talk about their experiences, those with negative experience may have refrained from participating, which obviously affects what types of narratives the study captures.

\section{Data collection}

The interviews were conducted during the final - sixth - semester of the participants' threeyear-long doctoral studies. As part of our narrative approach, one segment of the interview included participant's descriptions of photographs. We used a version of the photo elicitation method (Elliot, Reid, \& Baumfield, 2016), in order to vary the prompts used and allow the students to reflect on the material they had themselves chosen in advance. They were asked to select 3-5 photographs, either created by them or others, that capture what they will remember their PhD by. We instructed them to select not only elements directly pertaining to their studies, but to freely choose any aspect of the previous three years that they think they will remember in 
the future.

The aim was to get close to the participants' own views, which meant the interviews were very open and left a lot of room for individual interpretation. No definition of career was provided and they were allowed to choose those segments they considered important and/or relevant for the research project. They were not explicitly asked to focus on the positive or the negative experiences, or on any particular aspect of their PhD studies. Considering that the task was not to give an account of their PhD experience, but rather to select those elements that they think will remain as memories of their $\mathrm{PhD}$, it is possible that they chose to focus on the positive ones.

The accounts are given in retrospect, as the PhD is drawing to an end, and they have been passed through the filter of time - participants selected those elements that were most prominent for them at this particular time, characterised by the pressure of completing the dissertation. It is in that particular context that they chose to focus on certain elements, while leaving others in the background and/or in the past. One of the participants illustrated this reasoning when describing a photo of the view from his former office:

This one was the view of my office for a long time. So, for a couple of years, I think I had the best office for a while, with the view of the fjord and the trees [...] I moved to another place, that is not as nice as this one, that's why I'll remember this office.

\section{Analysis of data}

The selected photos did not form part of the analysis; rather, we used thematic analysis to inductively identify the prominent themes in the participants' descriptions of the photos. Their approach to selecting the photos varied; some arranged their photos in a particular order, to tell a story, but the majority selected individual aspects of their experience, which did not necessarily form one narrative. Therefore, we decided to view the descriptions of those photos as 45 separate data items and analyse them as such. At this stage, our study was exploratory and the aim of our analysis was to investigate how these students described their experiences, without a particular theoretical framework in mind (though still informed by our understandings of narrative interview as a method). Thematic analysis allows pattern recognition in data, while minimally organizing and describing the data set in detail (Braun \& Clarke, 2006).

Following Braun \& Clarke (2006) we open coded the transcribed interview segments, focusing on the meanings and value assigned to the PhD period (elements of studies, study/work environment, life in Denmark). This led to 16 individual codes, which we subsequently grouped into themes and sub-themes. We understood 'theme' as capturing something important about what the participants will remember about $\mathrm{PhD}$. A theme was coded as important if many participants mentioned it or if one or a few participants expanded on the topic, making it a significant portion of their account.

Three main themes resulted from this process: (1) personal and professional autonomy; (2) reminders of home; and (3) PhD work. The latter included four further sub-themes: (1) social environment; (2) tasks and skills; (3) final goal; and (4) enjoying the work. The final stage of analysis, according to Braun \& Clarke (2006) is writing up the report, which needs to 'tell the complicated story of your data' (p. 93). This phase involves relating the analysis back to the research question and literature and, in our case, it introduced another angle through which to look at our data. 


\section{The quest metaphor as conceptual framework}

Instead of simply relating our analysis to the existing research on this topic, such as the literature outlined in previous sections, we chose to use McCulloch's (2013) application of the 'quest' metaphor to PhD education to arrange our themes and sub-themes, as we recognised a certain match between these and McCulloch's conceptualisation. The 'quest' metaphor's elements offered a way to incorporate the aspects of PhD experience our participants described into one conceptual framework, without losing the complexity and diversity presented in the nine accounts. Furthermore, the metaphor's literary origins fit with our narrative approach to interviews and the desire of some of the participants to storify the photo descriptions.

McCulloch (2013) adapts the elements of a heroic quest to PhD education in the following way:

The precious object can have a variety of forms: award of the doctoral title, the knowledge gained/original contribution to knowledge, self-knowledge developed through reflection, solution/better definition of a particular issue, development of a new concept.

The long journey comprises the many opportunities for distraction and side-adventures offered by PhD study, but also personal travel undertaken during the degree. This is a personal change, characterized as the distance travelled.

The hero is the PhD student, facing problems and finding solutions to them. McCulloch (2013) does not elaborate on this, but our interpretation of the 'hero' is 'protagonist', the main character in a story and not necessarily someone who is admired and noted for great deeds or bravery.

A test / a series of tests are the more or less formalised challenges through which one 'becomes' rather than 'gets' a PhD.

The guardians are the examiners, acting as guardians for both the discipline and the university.

The helpers can be supervisors, research advisers, colleagues, librarians and laboratory staff, administrative staff, friends, family and those who provide information, data or commentary and critique on papers or thesis chapters.

\section{Findings}

The elements of the quest metaphor are not all equally present in our participants' accounts. Some, such as guardians, are rarely referred to, but this could be related to the fact that these students had not reached the PhD defence stage. Others seem to have a particular value for international students and can be understood as 'intensifiers' (Winchester-Seeto et al., 2014) that would arguably make their experience more complex compared to local students. One reason for this might be that we did not conduct the interviews with the metaphor's elements in mind nor did we seek to explore whether the participants could narrate their PhD experience as a quest. However, this metaphor seems to fit our participants' accounts to a significant degree, which led us to explore its usefulness for conceptualisations of $\mathrm{PhD}$ experience.

\section{Re 1. The precious object}

This element can be directly connected with the sub-theme 'final goal', which mainly refers to obtaining the title and graduating. Two of the participants mentioned this explicitly when describing their photos, one of which represented a graduation hat (traditionally created for PhDs 
in Germany and some other countries by their colleagues), and the other the reception organized for a fellow PhD who had graduated.

The next one is from the PhD defence of my colleague [...] this is also where I'm aiming for, because next year in March or so I will stand exactly at this place and say hopefully 'thank you' to everyone for giving me the title.

[...] it was the end of (a friend)'s PhD and we did this graduation hat with a lot of things [...] I put this because (a friend) had already asked for our other German friend to do this for us... so this would be like the sign of the ending of this.

At the same time, we could also interpret the work they had done - in labs or during fieldwork as the knowledge and skills they have obtained during their PhD studies, which is a form of a precious object that McCulloch refers to. Eight out of nine participants selected photos that represented this work, which belongs to our sub-theme 'tests \& skills'.

\section{The long journey}

In our initial coding, 'travels' fell under two themes: the main theme of 'personal \& professional autonomy' and the sub-theme 'tasks \& skills', which is part of the theme 'PhD work'. It is present in these two senses in our interviews:

a) as the travels that participants have undertaken during their PhD, both personal and workrelated (for conferences, PhD courses, external stays, etc.):

I've been doing quite a lot of travelling, both for work and for leisure during my PhD. Those were two of the coolest places I have been. [...] I like this photo quite a lot, and yes, that is more or less what I will be remembering also, like travelling, for work and without work, because Copenhagen has the advantage of being well-connected to Europe and to the world, so you can fly easily and cheaply and the work conditions here allow for extensive travelling...

b) as the personal and professional growth they have achieved during their PhDs. They mentioned particular skills they have improved, such as giving presentations, but also the confidence they have developed. Personally, many of them have become more independent, and three of them talked about having grown up in one way or another during their PhD. These are two types of profound changes that a journey represents in McCulloch's interpretation.

I thought that I was quite analytic and independent in terms of how I worked when I started my PhD, and then especially my supervisor taught me that there was still a long road to go to truly become independent. I also have a feeling that in general life I became much more critical in terms of that I want to question a lot if not everything... I have a feeling I'm so trained to always ask why, why, why, and how can it be and all that... I think I have kind of taken that thinking mentality over also into my personality a little, but I don't know if it's good or bad...

The first picture was taken in Norway actually, two weeks ago when I was on holidays [...] I also like to travel, and I think it's also the first time in my life that I travel alone for holidays... I'm quite independent and I think it was something that I had to learn during my PhD because we also need to travel for courses, for conference, and I think I became really independent. 
This element has some segments that could be interpreted as 'intensifiers' in the case of international students (in Denmark): the personal independence some of them achieved during the PhD period, due to living away from home for the first time.

This is our house and the keys, because we moved into our house in April. So yeah, having now our own house and garden and so on... This is again what I always wanted to do it but I didn't expect that it is so soon, during my PhD... But the salary in Denmark is quite nice and then also living in (this town) you just don't have the possibilities to spend that much money so you can afford doing this.

\section{The hero}

The interviews were narrative and entirely about the participants, so they inevitably and invariably were the protagonists, or the heroes, of the stories and accounts told. Six of our nine participants selected photos, which depicted themselves.

\section{The tests}

When linked to the theme of personal and professional autonomy, the accounts can be taken to represent stories of becoming and growth, through increased autonomy. Each of the photos represents elements of a journey that was coming to an end at the times when the interviews were conducted. The participants described photos that mainly referred to things they had done or experienced that had resulted in their growth. Although photos did not explicitly refer to difficulties or problems, the challenges encountered by the students as they worked towards a PhD were implied through the accounts of lab work and experiments. These were not always successful or in accordance with the participants' plans and ambitions.

[...] for now, unfortunately, the main thing I associate with my PhD is stress... [...] before, I was used to being a good student, it wasn't super difficult to achieve what I wanted and the PhD showed me the limit that I had to push against in terms of organisation, intelligence, reaching what you actually set yourself to do... That was a new experience in that extent and I think in that sense it's much much more stressful than I had imagined it should be and that I had wanted it to be...

This one is something that I was working for a lot of time, it took me like two years to make this picture. [...] It summarizes what happen in three years in a wind farm, but it took me a lot of time, it was a very frustrating project this one [...]This is the most frustrating project that I've ever had, but it's also very gratifying to see these results. I think my supervisor has this picture on his poster, in his office, cause it really took me a lot of time. Nowadays I know it shouldn't have, but it took me a lot of time to do it. [...] It took me way too long... way, way too long... but I learnt a lot by doing that. This picture I would remember all my life, lots of effort to make it and it looks beautiful... but it's - I'm still explaining it today...

However, photos representing the participants' lab or fieldwork also show their pride in the work they have done and, perhaps more importantly, the intrinsic enjoyment in conducting research and making new discoveries. Participants reported having enjoyed their experiments, despite the hard work these entailed, as well as the collaboration with their colleagues and supervisors.

I think that the most amazing thing is that I actually get paid to do what I believe in doing [...] I mean, I don't rescue whales every day, but it was part of what my heart really was af- 
ter when I started the position so... Being able to actually do something that I created myself and that people amazingly think is good enough to give me money to do it, I mean support me, that is something really, really cool and I don't know how many other jobs there would be where you would have so much freedom to design what you wanna do, and I think that's something amazing.

Although their PhDs had presented them with various challenges, the majority of the participants have found joy in their work.

\section{The guardians}

This element was for the most part absent from the photos. It was implied in the accounts of the two participants who talked about finishing their PhDs. However, in the second round of interviews, conducted after thesis submission and/or defence, several of the participants said they would change one of the photos used in the first interview for a photo of their dissertation or defence.

PhD supervisors could also be seen as guardians, but they were commonly not mentioned in our interviews in this context. They do appear occasionally as gatekeepers, opening doors to knowledge or opportunities:

This picture is one of the things that I enjoyed the most about working with my supervisor brainstorming with him. [...] He's very good at coming with new ideas and new approaches, that's something that we were doing a lot, just this sort of meetings where we were brainstorming and how to solve the problem in a different way... That's also something that I feel like it's hard with him because of that at the same time, that he has way too high expectations and you cannot really give them. [...] I don't know how many times, how many of those ideas that we brainstormed died because I guess I don't have enough time to implement all of them fully and follow the scientific procedure and prove they work and so on. That takes so long time that I have only managed to do just a few of them, and that's sometimes very high on yourself you know... even though it's very positive on one side, cause you learn that it is very positive to think outside the box, it's also at the same time very difficult for you to cope with the frustration of not being able to give what he expects...

My supervisor is an international guy, he comes from (country), has been studying in (country), did his PhD over there, then did a post-doc in (country) and came to Denmark for a post-doc position and soon will be moving to (city) in (country) for a research professorship. His international background very much influences international network and he has used that to the fullest to send me wherever he could. He apparently sees value in international relations and seeing something of the world, he sees it as a good opportunity to travel and gives me all the possibilities to do so.

Supervisors are gatekeepers of learning resources, specialist opinions and networks and they can choose which gates to open to their students (Lee, 2008). This can be a clear source of benefit, as in the second quotation presented above, where the supervisor had enabled our participant to travel extensively and expand his network. For the other participant, who shared his impressions in the first quotation above, the learning opportunities which his supervisor offers also present a form of pressure and frustration. He feels his performance has not always been at the level ex- 
pected by his supervisor, who in this sense becomes both a gatekeeper of more learning resources and a guardian of the discipline's standards.

\section{The helpers}

The helpers mentioned by the participants were their supervisors and their colleagues, mainly fellow PhDs. Five participants chose to include their colleagues in the photos in one way or another - office mates, office barbeque, Friday bar, colleagues who had become close friends. The socializing and non-work activities undertaken during their stay in the office were mentioned both in the photo descriptions and in the remainder of the interviews. One of the participants described these activities as what made the whole experience 'liveable' and it is interesting to note that, being mostly new to their workplaces, many participants found friends among their colleagues.

And this is one of the Friday bars... [...] It's a lot of friends, and some weirdos, of course, but, it is how it is [chuckling] in majority they are all cool guys, yeah, but this is also part of my life... maybe not every Friday but very often I'm there... It's a mixed life, a bit more liveable when you can go and just have a beer with the people that are kind of in the same situation as you are and then you can just say oh $f^{* *} k$ it, let's just have a beer... [...] it's quite important too.

This element falls under the main theme of 'PhD work' and, in particular, under two sub-themes: 'social environment' and 'enjoying the work'. Colleagues, friends (who are often peers), supervisors and social activities organised by and/or for PhD students are what created a certain kind of environment at the workplace and, at the same time, made the work and the PhD more enjoyable.

Moreover, some of the participants referred to or implied the emotional and moral support they received from home (in Denmark or abroad), which falls under the 'reminders of home' theme. Several of them mentioned it when describing the photos, for example connections to home (travelling home often), sending photos to the family back home, surroundings that remind them of home (e.g. the colourful facades in the centre of Copenhagen). Though not elaborated on much in the photo descriptions, it was more present in other segments of the interviews. Again, this is an element that could be interpreted as an 'intensifier'; Danish students that move to a different city for their PhD probably have similar experiences, but the 'support triangle' (Mantai \& Dowling, 2015) for international students covers a larger (physical) space. This 'triangle', comprising of family, colleagues and supervisors who offer emotional, social, and academic support, spans both Denmark and the home country.

And the final one is (airport) and you see the (location) and the typical corner I always get picked up by my parents whenever I go back to (my home country). This one resembles for me not so much the travelling like the Chinese Wall, but really the connection I have between Denmark and (my home country). Still I travel there pretty much every other month, several friends have visited me in Denmark from (my home country), either when I lived by myself or live now with my girlfriend. This one really resembles for me my connection still to (my home country). 


\section{Discussion and implications for practice}

Our findings show the variety of experiences that PhD students describe as the most memorable parts of their doctoral education. The complexity of these memories opens up interesting possibilities for employing the 'quest' metaphor to conceptualise PhD experience as more than a journey. Thinking about PhD studies using the elements of this metaphor can bring into relief the different dimensions of PhD experience that go beyond the research-related learning and activities.

In our small cohort of interviewed students, various forms and providers of social support have a prominent place. As already mentioned, this could be interpreted as in line with some of the previous research on international PhD students, such as Winchester-Seeto et al. (2014) and their concept of intensifiers, but our findings indicate that factors that intensify international students' experience do not necessarily always have a negative value. Winchester-Seeto et al. (2014) address intensifiers as those factors that make difficulties for international PhD students more pronounced. In our case, participants rarely referred to challenges when describing their photos. Consequently, the intensifiers we identify in our findings point to positive developments; for instance, personal growth may be more intense in international students as they face a new academic and a new national culture.

Home ties and support systems, labelled as 'Separation from support' by Winchester-Seeto et al. (2014), are among the factors that make the PhD experience more challenging for international students. In our interviews, all the PhD students alluded to these factors by mentioning work colleagues and social activities in the workplace, but these are presented as not necessarily negative or positive in themselves. It is simply something that is there and characterises the experience of these international PhD students. The timing of our interviews might have influenced this, as our participants were close to finishing their studies and we can assume that they had already established their support systems. However, these findings indicate that further - longitudinal - study on this topic is needed to shed more light on international students' need for support and perceptions of it.

Our findings mostly refer to social support and the issue of separation from it, which indicates that universities should pay particular attention to the value that the social environment may have for internationals. One of the ways to conceptualise support of PhD students may be the 'support triangle' suggested by Mantai and Dowling (2015), but the quest metaphor could also prove to be a useful tool here, imagining supporters as 'helpers' of the hero on his/her quest. Drawing on more literary examples could enable us to depict more nuances of this support and different types of supporters.

Furthermore, it could provide an interesting way to conceptualise supervisors' roles, distinguishing between the 'guardian' and 'helper' aspects. Our findings indicate that using the metaphor of quest could be useful for thinking about the experience of PhD students. In particular, it could be useful for PhD supervisors, enabling them to think of doctoral studies not as a sequence of discrete phases, but rather as a more complex and meandering experience. They could indeed see their PhD students as heroes on a personal and professional quest to capture their precious object of desire, be it the degree, skills, knowledge or something else. This metaphor could be used in training and workshops for PhD supervisors, where they could be prompted to write a story of a PhD quest. Also, they could use this metaphor in supervision, giving the same task to their stu- 
dents and then collaboratively comparing the resulting quest stories. The quest metaphor and its elements could provide a framework and prompts for students to tell their story in a short format for collecting research data. Such exercises would be more time-saving than an in-depth interview, while still providing an opportunity to cover all the potentially important segments.

The quest metaphor offers a fairly broad overview of the PhD experience and, though possibly useful as a starting point, does require further employment of other conceptual models and theories to zoom in on the particularities of individual experiences. Metaphors can 'evoke unintended interpretations' because the meaning is implied rather than explicitly discussed (Kobayashi, 2014 , p. 59). Also, uncritical and inconsistent use of metaphors may lead to a mismatch between students' and their supervisors' conceptions of research and affect progress (Pitcher, 2010). On the one hand, the quest metaphor does seem to grasp the complexity, for instance that supervisors can be both helpers and guardians and that personal growth is achieved both through the journey and the challenges faced. On the other hand, the metaphor has a tendency to make us focus on the plot more than the process, which could perhaps be linked to its literary origins. It can indeed encompass all the twists and turns of the $\mathrm{PhD}$ undertaking and all the actors in it, but it does not appear to take a deeper look into the hero's feelings and thoughts, at least not in the way McCulloch (2013) presents it.

As pointed out by Kobayashi (2014), metaphors have different associations for different people. Some people may interpret a quest as predestined, with a predictable happy ending despite much hardship one suffers before reaching it. A journey may not be seen as travelling from $A$ to $B$ as McCulloch suggests, but it could be an adventure where decisions on the direction are taken from day-to-day, and the end goal is unknown. If interviews or narratives are produced by $\mathrm{PhD}$ students based on the quest metaphor, then the challenges would appear through the tests, and the drivers or rewards as either the precious object or overcoming the tests. The latter would most probably emerge as extrinsic motivational factors, while the joy of learning new things about the world may not be brought out through the quest metaphor. The motive of finding pleasure in work does figure in our participants' accounts, when referring to different dimensions of their work: the experiments and fieldwork, the social environment and interaction at the workplace, the beauty of the physical surroundings. It can be identified under different elements of the metaphor, such as the precious object, the journey, the helpers and even the tests. However, the quest metaphor's focus on the plot seems to allow this important element of PhD experience to somewhat remain in the background.

Here it is worth noting that we could fit the joy and excitement from the narrative interviews into the quest metaphor, but the respondents may not have focused as much on the joy if the interviews were structured around the quest metaphor. When juxtaposing the two metaphors, the quest and the journey, we would suggest that the quest metaphor makes us focus more on extrinsic motivations, while the journey metaphor better includes the intrinsic motivation, with reference to Self Determination Theory (Ryan \& Deci, 2000). Another distinction may be that the quest focuses more on the context of the PhD process, while the journey focuses on the content or the cognitive development, dependent on individual interpretations of the metaphors, as suggested by Angela Brew (2017). One more difference between the two metaphors refers to the degree in which each prompts the author or interviewee to think about different aspects, and hence the quest metaphor may have advantages in teaching settings or collection of data in written form, while the journey metaphor may have advantages in more open interviews. 


\section{Conclusion}

In this article we aimed to explore the use of the quest metaphor as a means to grasp the complexity of the experiences of international PhD students in Denmark, within our broader longitudinal study of the meanings PhD experience has for future career. We believe that the 'quest' metaphor offers an interesting way to conceptualise the experience of doctoral students and that, with some limitations, it can be a useful tool in PhD supervision practice. Its elements provide a structured, yet sufficiently open framework within which to view the story of a doctoral education. This story can be told either by the student or by the supervisor and help both gain insight into the other one's expectations from the process. In the case of international PhD students the category of 'helpers' can be particularly informative. However, any individual student's story of their PhD 'quest' is likely to change at different points of the studies and this aspect needs to be taken into account. Further research into the practical usage of the 'quest' metaphor, possibly in combination with the 'journey' metaphor, is needed to shed more light on this topic, preferably as part of longitudinal studies of $\mathrm{PhD}$ experiences.

\section{References}

Barron, D., \& Zeegers, M. (2006). Subjects of Western education: Discursive practices in Western postgraduate studies and the construction of international student subjectivities. The Australian Educational Researcher, 33(2), 77-96.

Braun, V., \& Clarke, V. (2006). Using thematic analysis in psychology. Qualitative Research in Psychology, 3(2), 77-101.

Brew, A. (2017). Personal communication, EARLI biennial conference, Tampere, Finland, August 2017.

Bøgelund, P. (2015). How supervisors perceive PhD supervision-And how they practice it. International Journal of Doctoral Studies, 10, 39-55.

Cargill, M. (2000). Intercultural postgraduate supervision meetings: An exploratory discourse study. PROSPECT-ADELAIDE-, 15(2), 28-38.

Cotterall, S. (2013). More than just a brain: emotions and the doctoral experience. Higher Education Research \& Development, 1-14.

Danish Council for Research Policy (2011) Danmarks Forskningspolitiske Råds positionspapir for ph.d./forskerkarriere. København: Danmarks Forskningspolitiske Råd. Retrieved on 24.07.2017. from http://ufm.dk/forskning-og-innovation/rad-og-udvalg/danmarksforsknings-og-innovationspolitiske-rad/danmarks-forskningspolitiske$\mathrm{rad} /$ debat/danmarks-forskningspolitiske-raad-positionspapir-ph-d-forskerkarriere22062011.pdf

Elliot, D. L., Reid, K., \& Baumfield, V. (2016). Capturing visual metaphors and tales: innovative or elusive? International Journal of Research \& Method in Education, 0(0), 1-17.

Elliot, D. L., Reid, K., \& Baumfield, V. (2016). Beyond the amusement, puzzlement and challenges: an enquiry into international students' academic acculturation. Studies in Higher Education, 41(12), 2198-2217. 
Ingleton, C., \& Cadman, K. (2002). Silent Issues for International Postgraduate Research Students' Emotion and Agency in Academic Success. The Australian Educational Researcher, 29 (1), 93-113.

Kiley, M. (2003). Conserver, Strategist or Transformer: The experiences of postgraduate student sojourners. Teaching in Higher Education, 8 (3), 345-356.

Kobayashi, S. (2014). Learning dynamics in doctoral supervision. (PhD Thesis), University of Copenhagen, Copenhagen, Denmark.

Lee, A. (2008). How are doctoral students supervised? Concepts of doctoral research supervision. Studies in Higher Education, 33 (3), 267-281.

Lee, A., \& Green, B. (2009). Supervision as metaphor. Studies in Higher Education, 34 (6), 615630.

Manathunga, C. (2014). Intercultural postgraduate supervision: Reimagining time, place and knowledge. London: Routledge.

Mantai, L., \& Dowling, R. (2015). Supporting the PhD journey: insights from acknowledgements. International Journal for Researcher Development, 6(2), 106-121.

McAlpine, L., Amundsen, C., \& Turner, G. (2013). Constructing post-PhD careers: negotiating opportunities and personal goals. International Journal for Researcher Development, 4 (1), $39-54$.

McAlpine, L., \& Emmioğlu, E. (2015). Navigating careers: perceptions of sciences doctoral students, post-PhD researchers and pre-tenure academics. Studies in Higher Education, 40 (10), 1770-1785.

McCulloch, A. (2013). The quest for the PhD: a better metaphor for doctoral education. International Journal for Researcher Development, 4 (1), 55-66.

Mosneaga, A., \& Winther, L. (2013). Emerging talents? International students before and after their career start in Denmark. Population, space and place, 19, 181-195.

Pitcher, R. (2010). The Self in Research and Other Matters: A Study of Doctoral Students' Conceptions. International Journal for Researcher Development, 1 (3), 248-256.

Ryan, R. M., \& Deci, E. L. (2000). Intrinsic and extrinsic motivations: Classic definitions and new directions. Contemporary Educational Psychology, 25 (1), 54-67.

Universities Denmark (2013) Satsningen på PhD Uddannelse. Copenhagen, Retrieved 2017.07.24 from http://dkuni.dk/Politik/Publikationer-og-notater

Walsh, E. (2010). A model of research group microclimate: environmental and cultural factors affecting the experiences of overseas research students in the UK. Studies in Higher Education, 35 (5), 545-560.

Winchester-Seeto, T., Homewood, J., Thogersen, J., Jacenyik-Trawoger, C., Manathunga, C., Reid, A., \& Holbrook, A. (2014). Doctoral supervision in a cross-cultural context: issues affecting supervisors and candidates. Higher Education Research \& Development, 33 (3), 610-626. 